\title{
Measuring Business Cycle Time
}

\section{Citation}

Stock, James H. 1987. Measuring business cycle time. Journal of Political Economy 95(6): 1240-1261.

\section{Published Version}

http://dx.doi.org/10.1086/261513

\section{Permanent link}

http://nrs.harvard.edu/urn-3:HUL.InstRepos:3425950

\section{Terms of Use}

This article was downloaded from Harvard University's DASH repository, and is made available under the terms and conditions applicable to Other Posted Material, as set forth at http:// nrs.harvard.edu/urn-3:HUL.InstRepos:dash.current.terms-of-use\#LAA

\section{Share Your Story}

The Harvard community has made this article openly available.

Please share how this access benefits you. Submit a story.

\section{Accessibility}




\section{CHICAgO JOURNALS}

Measuring Business Cycle Time

Author(s): James H. Stock

Source: The Journal of Political Economy, Vol. 95, No. 6 (Dec., 1987), pp. 1240-1261

Published by: The University of Chicago Press

Stable URL: http://www.jstor.org/stable/1831120

Accessed: $25 \overline{/ 11 / 200911: 57}$

Your use of the JSTOR archive indicates your acceptance of JSTOR's Terms and Conditions of Use, available at http://www.jstor.org/page/info/about/policies/terms.jsp. JSTOR's Terms and Conditions of Use provides, in part, that unless you have obtained prior permission, you may not download an entire issue of a journal or multiple copies of articles, and you may use content in the JSTOR archive only for your personal, non-commercial use.

Please contact the publisher regarding any further use of this work. Publisher contact information may be obtained at http://www.jstor.org/action/showPublisher?publisherCode=ucpress.

Each copy of any part of a JSTOR transmission must contain the same copyright notice that appears on the screen or printed page of such transmission.

JSTOR is a not-for-profit service that helps scholars, researchers, and students discover, use, and build upon a wide range of content in a trusted digital archive. We use information technology and tools to increase productivity and facilitate new forms of scholarship. For more information about JSTOR, please contact support@jstor.org. 


\title{
Measuring Business Cycle Time
}

\section{James H. Stock}

Harvard University

\begin{abstract}
The business cycle analysis of Burns and Mitchell and the National Bureau of Economic Research presumed that aggregate economic variables evolve on a time scale defined by business cycle turning points rather than by months or quarters. Do macroeconomic variables appear to evolve on an economic rather than a calendar time scale? Evidence presented here suggests that they do. However, the estimated economic time scales are only weakly related to business cycle time scales, providing evidence against the view underlying traditional business cycle analysis.
\end{abstract}

Understanding business cycles has been and continues to be a major challenge of empirical macroeconomic research. Although the theoretical perspectives of modern research programs that examine fluctuations in output, employment, investment, and prices differ greatly, these programs share the econometric assumption that macroeconomic variables evolve naturally on a fixed calendar time scale (e.g., monthly or quarterly). This modern view stands in sharp contrast to the traditional business cycle analysis of Burns and Mitchell (1946) and the National Bureau of Economic Research (NBER). In the latter approach, the individual business cycle is treated as a distinct unit of economic time: in aggregate, economic variables are viewed as related

I thank Olivier Blanchard, Stephen Jones, Angelo Melino, Jay Patel, Sherwin Rosen, Mark Watson, the participants in the 1985 NBER Summer Institute on Financial Markets, and two anonymous referees for helpful comments on previous drafts. I also thank James J. Heckman for useful suggestions and for pointing out the relevance of the research in Chetty and Heckman (1986). I am particularly grateful to Thomas Rothenberg, who supervised my University of California, Berkeley, Ph.D. dissertation, which this article extends. Stephen Johnson provided skillful research assistance, and the National Science Foundation provided support under grant SES-84-(08797. 
in a regular fashion from one stage of the cycle to the next rather than from month to month. Because business cycles have different lengths, the appropriate time scale on which to analyze these cyclical comovements was seen to be based not on months, quarters, or some other unit of calendar time but on the business cycle itself.

In their attempt to analyze macroeconomic relationships in business cycle rather than in calendar time, Burns and Mitchell averaged monthly data to estimate the value a variable would attain were it observed at regular intervals in business cycle time. Unfortunately, this "phase-averaging" technique provided an inadequate basis for formal statistical inference, so that classical statistical techniques could not help to resolve the historical debate over the use of calendar time, business cycle time, or, more generally, any data-based macroeconomic time scale. ${ }^{1}$ But did Burns and Mitchell have an insight into important empirical regularities among macroeconomic variables over the course of the cycle that are masked when economic time series are examined on a monthly or quarterly basis?

In this paper, I reexamine the possibility that macroeconomic variables evolve on a cyclical time scale. Conventional macroeconometric analysis typically assumes time-series variables to be generated by a linear time-invariant discrete-time process, say a vector autoregression. I adopt this starting point with two important modifications. First, latent economic variables are assumed to evolve according to a linear time-invariant process in economic rather than in calendar time. The relationship between economic and calendar time in turn depends on the economic history of the process (specifically, on either exogenous or predetermined variables), such as whether the economy has been in a cyclical expansion or contraction. Second, the linear process is defined in continuous economic time. This has two advantages over a discrete-time formulation: it permits an explicit treatment of the correlations induced by using data that have been temporally aggregated, and it is logically necessary if the transformation between economic and calendar time is taken to be continuous. This "time deformation" model is presented in Section I.

The idea that economic and calendar time might differ has appeared before in at least three other contexts. First, this proposition has been discussed in a number of studies of the hyperinflations of the 1920s. In examining Cagan's (1956) model of money demand, Allais (1966) proposed that money evolves on a time scale based on an

\footnotetext{
${ }^{1}$ Calling the work of Burns and Mitchell (1946) "measurement without theory," Koopmans (1947) argued that this research program lacked both an economic theory on which to base the investigations and a statistical theory with which to evaluate the results. Despite this lack of associated statistical theory, phase averaging is still occasionally employed as a research tool (e.g., Schultz 1981; Friedman and Schwartz 1982).
} 
index of past total outlays. Barro (1970) derived a model of wage payments (and thus money demand by firms) in which the payment timing interval depended on the (smoothed) inflation rate, suggesting that the appropriate time scale for analyzing money demand depends on inflation. Flood and Garber (1980), also arguing that decisions concerning money balances will be made more often during periods of high inflation, examined the German hyperinflation by combining monthly data for the moderate inflation period before 1923 with weekly data for the later hyperinflationary period.

A second motivation for searching for empirical evidence of time deformation in aggregate data is provided by Chetty and Heckman's (1986) pioneering analysis of nonlinearities in aggregate output supply and factor demand equations. In their model, firms invest in, enter, or exit a competitive industry depending on product and factor prices and on production opportunities peculiar to each firm. Allowing for different vintages of capital and aggregating over firms, they derive lag structures in which the lag scheme depends not simply on the calendar time period separating the observations but on the intervening economic history. Their model constitutes an important foundation for this investigation of business cycle time since it provides both an empirical example of the potential importance of time scale nonlinearities and a theoretical explanation for Neftçi's (1984) observed asymmetry between cyclical expansions and contractions in unemployment, an issue investigated in more detail below.

In a third treatment of the time deformation concept, Clark (1973) suggested that the natural time scale for the evolution of commodity prices was one based on information flows rather than calendar time, which, he showed, could explain the heavy-tailed distribution of returns on cotton futures. ${ }^{2}$ The intent of this paper differs from these applications, however, focusing on the interpretation of the traditional techniques of business cycle analysis.

I study two classes of transformations from calendar to economic time. The first class, presented in Section II, addresses the issue of whether there is evidence in favor of business cycle time and includes three different specifications. Two of the specifications address the question of whether the asymmetry between the lengths of expansions and contractions identified by Neftçi (1984) is reflected in differ-

\footnotetext{
${ }^{2}$ Clark (1973) modeled price changes as a subordinated stochastic process, where the directing process (the random time scale increments) was lognormally distributed (see also Mandelbrot 1973). With the theory of a subordinated stochastic process, many continuous-time stochastic processes can be written as a Weiner process with random time substitution (Brieman 1969; Feller 1971). Similarly, time scale transformations can make certain nonhomogeneous point processes appear to be homogeneous Poisson (Cox and Lewis 1966; Lewis 1972).
} 
ent rates of evolution of aggregate variables. The remaining member of this class is the time scale transformation implicit in phase averaging, where the time scale is determined by cyclical turning points. The second class of time scale transformations addresses the question of whether aggregate variables evolve on an economic time scale that differs both from calendar time and from business cycle time. The transformations of this class depend on predetermined variables.

In Section III, I present some simple multivariate diagnostic tests for detecting time deformation. These tests look for evidence that these variables evolve at different rates during growth expansions than during growth recessions. When the tests are applied to Friedman and Schwartz's (1982) annual data on income, money, inflation, and nominal interest rates from 1869 to 1975 , the evidence is mixed: inflation, interest rates, and, to a lesser extent, money indicate strong nonlinear relationships to the expansion/contraction time scale, while real per capita gross national product (GNP) does not.

Using a Kalman filtering algorithm developed in Stock (1983, 1985), in Section IV, I estimate the parameters of a variety of time scale transformations jointly with the parameters describing the evolution of the latent process. The estimated time scales indicate only a limited relationship to the expansion/contraction switching variables or to the implicit NBER time scale. However, there is strong evidence that the aggregate variables evolve on an economic time scale other than business cycle or calendar times. The two key variables determining these time scales are the rate of interest and the growth rate of GNP: when interest rates are high and GNP growth is strong, economic time appears to "speed up." The conclusions are summarized in Section V.

\section{Stochastic Processes in Economic Time}

The time deformation model provides an alternative approach to modeling economic time series in which latent variables evolve linearly in economic time but are observed on the nonlinear transformation of that time scale known as calendar time. This model has two components that must be specified: the equations that the latent variables obey in economic time and the relationship between calendar and economic time. Let $\boldsymbol{\xi}(s)$ be a vector of random variables defined on the economic time scale $s$ and let calendar time $(t)$ and economic time be related by $s=g(t)$. The key assumption of the model is that a variable observed at a point in calendar time (i.e., a stock) can be represented as $\boldsymbol{\xi}(g(t))$. When a variable is measured as a sum over an interval of time, it is modeled as the average of the instantaneous calendar time process from $t-1$ to $t$. That is, depending on whether 
the variable is a stock or a flow, the observable discrete calendar time variable $\mathbf{Y}_{t}$ is

$$
\begin{gathered}
\text { stocks: } \mathbf{Y}_{t}=\boldsymbol{\xi}(g(t)), \\
\text { flows: } \mathbf{Y}_{t}=m^{-1} \sum_{i=1}^{m} \boldsymbol{\xi}\left[g\left(t-1+\frac{i}{m}\right)\right] \rightarrow \int_{t-1}^{t} \boldsymbol{\xi}(g(\tau)) d \tau .
\end{gathered}
$$

In the empirical work below, I assume that $\boldsymbol{\xi}(s)$ is an $n$-dimensional stochastic process that obeys an $r$ th-order stable vector stochastic differential equation with a possible deterministic time trend. Then $\boldsymbol{\xi}(s)$ has the continuous (economic) time representation

$$
\begin{aligned}
d\left[D^{r-1} \boldsymbol{\xi}(s)\right]= & {\left[\mathbf{A}_{1} D^{r-1} \boldsymbol{\xi}(s)+\ldots+\mathbf{A}_{r} \boldsymbol{\xi}(s)\right.} \\
& \left.+\boldsymbol{\beta}_{0}+\boldsymbol{\beta}_{1} s\right] d s+d \zeta(s),
\end{aligned}
$$

where $\mathbf{A}_{1}, \ldots, \mathbf{A}_{r}$ are $n \times n$ matrices of coefficients, $\boldsymbol{\beta}_{0}$ and $\boldsymbol{\beta}_{1}$ are $n \times 1$ coefficient vectors, $D$ is the mean square differential operator, and $\zeta(s)$ is an $n$-dimensional noise process with Gaussian increments, where $E\left[d \zeta(s) d \zeta\left(s^{\prime}\right)^{\prime}\right]=\boldsymbol{\Sigma} d s, s=s^{\prime}$, and zero otherwise. ${ }^{3}$

The remaining feature of the time deformation model is the time transformation itself. Four general properties are desirable for the time transformation. First, to be econometrically tractable, $\Delta g(t)$ must not depend on current or future values of $\mathbf{Y}_{t}$. Second, economic and calendar time should proceed in the same direction so that $0<\Delta g(t)$ $<\infty$ for all $t$, where $\Delta g(t)=g(t)-g(t-1)$. Third, the unknown parameters of the time scale transformation should be identified. In particular, linear transformations of the time scale clearly will not be identified since this would simply entail relabeling the time scale from, for example, quarters to years. Thus I set $g(0)=0$ and $T^{-1} \Sigma \Delta g(t)=1$ (where $T$ refers to the number of observations) so that, on average, a unit of economic time corresponds to a unit of calendar time. Fourth, estimation is simplified substantially if the time scale transformation is continuous in its unknown parameters. The parameterization adopted in this paper has these four properties. Specifically, $\Delta g(t)$ is given by

$$
\Delta g(t)=\frac{\exp \left(\mathbf{c}^{\prime} \mathbf{z}_{t-1}\right)}{T^{-1} \sum_{r=2}^{T} \exp \left(\mathbf{c}^{\prime} \mathbf{z}_{r-1}\right)},
$$

where $\mathbf{z}_{t-1}$ is an $m$-dimensional vector of variables observed by time $t$ -1 and $\mathbf{c}$ is an $m$-dimensional vector of unknown parameters. Note

${ }^{3}$ If $g(t)$ is continuous, then the latent process must evolve continuously in economic time for the model to be well defined. For a complete discussion of (2), see Bergstrom $(1976,1983)$. 
that if $\mathbf{c}=0$, then $\Delta g(t)=1$ and there is no time deformation. In addition, using a Taylor series expansion of (3) in $\mathbf{c}$ around $\mathbf{c}=0$, one finds that

$$
\Delta g(t) \cong 1+\mathbf{c}^{\prime}\left(\mathbf{z}_{t-1}-\overline{\mathbf{z}}\right),
$$

where $\overline{\mathbf{z}}$ denotes the sample average of $\mathbf{z}_{t-1}$. For more pronounced time deformations, the exponential form restricts $\Delta g(t)$ to be positive and finite. ${ }^{4}$

\section{Cyclical Time Scale Transformations}

This section presents three cyclical time scale transformations studied empirically below. The first is the one implicit in Burns and Mitchell's (1946) computations of phase averages. This transformation is a piecewise linear relationship between business cycle time and calendar time, where the slopes of the different linear segments depend on the length of the current recession or expansion. The other two transformations depend only on whether the economy is in an expansion or a contraction.

\section{The NBER Time Scale}

Burns and Mitchell's phase-averaging procedure involved breaking each expansion and contraction into four parts of roughly equal lengths in months. Accordingly, each business cycle was assigned nine "stages": the trough, the three periods leading to the fifth stage (the peak), and the three periods leading to the ninth stage, the subsequent trough, which is also the first stage of the next cycle. The transformed or "phase-averaged" data are the average of the observations over the months that fall into the relevant stage of the cycle. Underlying this transformation, then, is the assumption that the change in business cycle time (i.e., the length of the stages of the cycle) is proportional to the change in the calendar time scale with a propor-

${ }^{4}$ The discrete-time representation of $\mathbf{Y}_{t}$ for a first-order process satisfying (1a) and (2) is given in the Appendix. In general, $\mathbf{Y}_{\ell}$ will exhibit two important departures from linear time-series models. First, the serial dependence in calendar time will differ from one period to the next, depending on the amount of economic time that has elapsed. Second, the observable process will be conditionally heteroscedastic. In this respect, the time deformation model is similar to Engle's (1982) Autoregressive Conditional Heteroscedasticity (ARCH) models. Indeed, empirical findings of conditional heteroscedasticity such as Engle's (1982) or those concerning stock returns debated by Pindyck (1984) and Poterba and Summers (1986) are consistent with models in which economic and calendar time differ. See Stock (1985) for further discussion of the relationship between time deformation models and ARCH models and switching regression models. 


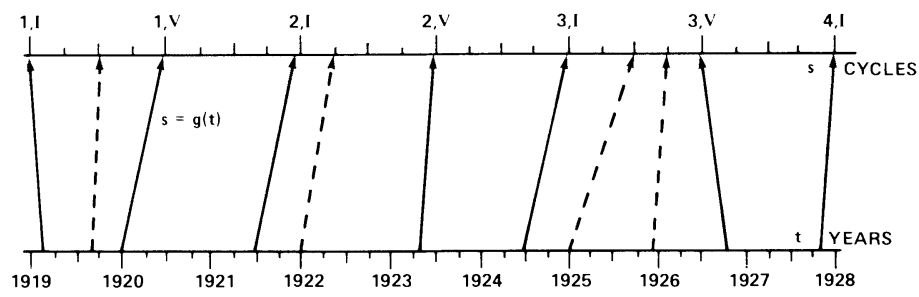

Fig. 1.-Calendar and NBER-dated business cycle time scales

tionality factor that changes from expansion to contraction and from cycle to cycle. ${ }^{5}$

A segment of Burns and Mitchell's (1946, app. A) chronology for business cycles between 1919 and 1927 is portrayed in figure 1 . The upper scale denotes cyclical time; the units are stages of the cycle. The origin has been set so that the trough of March 1919 is cycle 1 , stage I. The heavy arrows denote the dates of the cyclical turning points over this period (March 1919 [trough], January 1920, July 1921, May 1923, July 1924, October 1926, and November 1927). The dashed arrows denote the mapping $g(t)$ for selected calendar time dates using Burns and Mitchell's reported chronology. For example, December 1925 fell in the third stage of cycle 3.

The relative "speeds" of business cycle and calendar times are determined by the amount of cycle time that has elapsed in a unit of calendar time. Referring to figure 1, during 1925 a relatively short amount of business cycle time elapsed, so during this period economic processes would appear in calendar time to evolve relatively slowly. In contrast, the observable process would have evolved relatively quickly during 1919. In general, if $\Delta g(t)$ is less (more) than its average over the sample, then the process is evolving more slowly (quickly) than average.

When the transformation in figure 1 is formalized, the change in business cycle time during a unit of calendar time is four (stages) divided by the number of months in the current contraction or expansion; let this ratio be $r_{i e}$ for the expansion and $r_{i c}$ for the contraction in the $i$ th cycle. Letting $I_{t}$ be one in an expansion and zero in a contraction, and letting $J_{i t}$ be one if month $t$ falls in the $i$ th of the $M$ business cycles in the sample, the NBER time scale transformation is

$$
\Delta g(t)=\sum_{i=1}^{M}\left[r_{i e} I_{t}+r_{i c}\left(1-I_{t}\right)\right] J_{i t} .
$$

The transformation (5) was computed for 1869-1975 using Moore's (1983) business cycle chronology and is plotted in figure 2

${ }^{5}$ Burns and Mitchell (1946, chap. 2, app. A) and Friedman and Schwartz (1982, chap. 3) provide extensive discussions of phase averaging. 


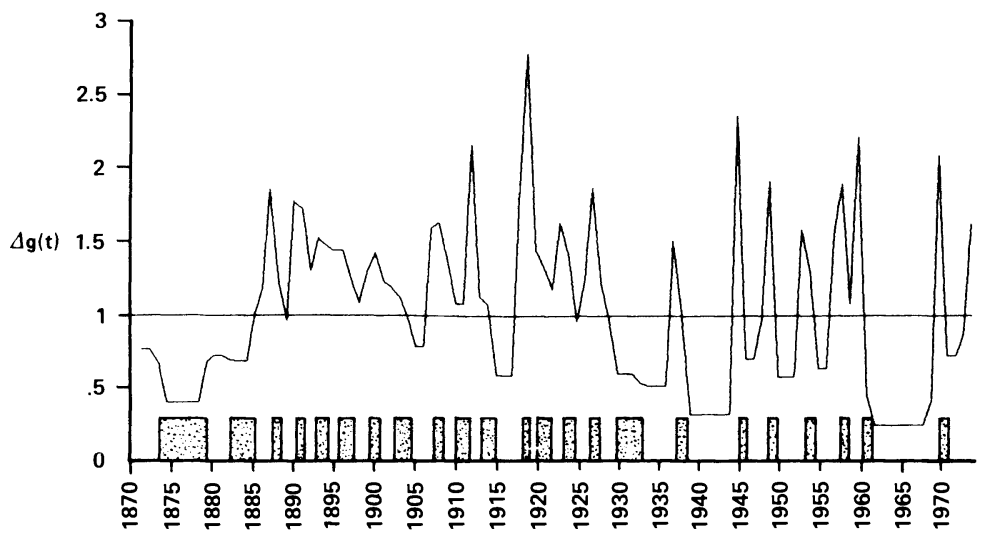

FIG. 2.-NBER time scale transformation. Shaded areas along the axis denote NBER-dated recessions.

after renormalization so that $T^{-1} \Sigma \Delta g(t)=1$. Large values of $\Delta g(t)$ correspond to short expansions or contractions. For instance, the short expansion during 1919 in figure 1 appears in figure 2 as a tall spike. The sustained high value of $\Delta g(t)$ during the final decade of the nineteenth century indicates the rapid succession of booms and panics. In contrast, the Great Depression, the recovery during World War II, and the prolonged growth during the 1960s are episodes of relatively long expansions or contractions and, thus, small values of $\Delta g(t)$. Finally, the alternating high and low values of $\Delta g(t)$ during the late 1940s and 1950s reflect the postwar experience that expansions have tended to be longer than contractions.

Although its simplicity makes the NBER time scale appealing, it depends on future turning points and thus violates the first of the four requirements for $\Delta g(t)$ set out in Section I. Consequently, I will also consider two cyclical time scales that can be determined by observing only past values of economic variables.

\section{Contraction/Expansion Time Scales}

The remaining two cyclical time scales address the possibility that economic time progresses faster during expansions than during contractions. The first is based on a variable that indicates whether the economy is expanding or contracting, as measured by the growth rate of real per capita GNP, $\Delta y_{t}$ :

$$
I_{t}= \begin{cases}1 & \text { if } \Delta y_{t} \geq 0 \\ 0 & \text { if } \Delta y_{t}<0\end{cases}
$$

On examining the switching variable (6) (defined using postwar U.S. unemployment rather than GNP), Neftçi (1984) concluded that busi- 
ness cycles were asymmetric. However, when a series exhibiting consistent growth (such as GNP) is used as the basis for the switching variable, this asymmetry might arise simply because the series has been improperly detrended (see DeLong and Summers 1986; Falk 1986). Consequently, I also consider a "growth cycle" switching variable indicating whether the economy is experiencing a growth expansion or contraction:

$$
I G_{t}= \begin{cases}1 & \text { if } \Delta y_{t} \geq \overline{\Delta y} \\ 0 & \text { if } \Delta y_{t}<\overline{\Delta y}\end{cases}
$$

When the time scale transformation (3) depends on a single switching variable, it has a particularly simple form. When (3) is used and $z_{t-1}=I G_{t-1}$, the transformation is given by

$$
\Delta g(t)=\frac{\exp \left(c I G_{t-1}\right)}{1+[\exp (c)-1] \overline{I G}},
$$

where $I G=T^{-1} \sum I G_{t-1}$. The time scale transformation corresponding to (6) also has the form (8), with $I_{t-1}$ and $\bar{I}$ replacing $I G_{t-1}$ and $\overline{I G}$, respectively.

\section{Multivariate Tests for Business Cycle Time}

The Tests

The estimation of time deformation models is computationally burdensome. In this section, I therefore present and implement two easily executed regression-based diagnostic tests for time deformation. The proposed tests are developed for time transformations with local linearizations of the form (4), where $c$ and $z_{t-1}$ are scalars. The tests, developed in the Appendix, look for nonlinearities in the expectation of $\mathbf{Y}_{t}$ conditional on lags of $\mathbf{Y}_{t}$ and $z_{t}{ }^{6}$

The first test entails estimating an unrestricted system of equations specified in the levels of the variables, including a time trend:

$$
\begin{aligned}
\mathbf{Y}_{t}= & \mathbf{C}_{0}+\mathbf{C}_{1} t+\mathbf{C}_{2}(L) \mathbf{Y}_{t-1}+\mathbf{C}_{3}(L) \tilde{z}_{t-1} \\
& +\mathbf{C}_{4}(L) \tilde{z}_{t-1} \mathbf{Y}_{t-1}+\mathbf{C}_{5} t \tilde{z}_{t-1}+\mathbf{C}_{6} \sum_{r=1}^{t-1} \tilde{z}_{r}+\mathbf{u}_{t},
\end{aligned}
$$

where $\mathbf{C}_{2}(L), \mathbf{C}_{3}(L)$, and $\mathbf{C}_{4}(L)$ are matrix polynomials of order $p$ in the lag operator $L$ and $\tilde{z}_{t-1}=z_{t-1}-\bar{z}$. If $\mathbf{c}=0$, then the coefficient

${ }^{6}$ The tests generalize to multivariate systems the univariate tests for time deformation proposed in Stock (1983). The price of the simplicity of these tests is that the orthogonality conditions tested have a much higher dimension than $\mathbf{c}$. Thus they might detect nonlinear specifications other than time deformation, while their power against the time deformation alternative could be low. For related tests, see Neftçi (1986). 
matrices $\mathbf{C}_{3}(L), \mathbf{C}_{4}(L), \mathbf{C}_{5}$, and $\mathbf{C}_{6}$ will not enter into the multivariate specification. Thus estimating (9) by least squares and testing whether these coefficients all equal zero provides a test for nonlinear conditional expectations of the type generated by the time deformation model.

Since the variables might reasonably be modeled as having a stochastic rather than a deterministic trend, the second test is based on estimating a version of (9) specified in first differences of $\mathbf{Y}_{t}$ rather than in levels:

$$
\Delta \mathbf{Y}_{t}=\mathbf{C}_{0}+\mathbf{C}_{1} \Delta \mathbf{Y}_{t-1}+\mathbf{C}_{2}(L) \tilde{z}_{t-1}+\mathbf{C}_{3}(L) \tilde{z}_{t-1} \Delta \mathbf{Y}_{t-1}+\mathbf{u}_{t} .
$$

The second test examines whether $\mathbf{C}_{2}(L)$ and $\mathbf{C}_{3}(L)$ differ from zero.

\section{The Data}

A long time series of economic data containing many business cycles was chosen to address the question of the existence of a cyclical time scale. The data are a subset of the Friedman-Schwartz (1982, table 4.8) U.S. data set and consist of annual observations from 1869 to 1975 on income, the money stock, population, the rate of inflation (based on the implicit price deflator), and the short-term commercial paper rate. Income and money were transformed to be the logs of these variables on a real, per capita basis.

\section{Test Results}

The tests are based on the time scale transformation (8), addressing the possibility that economic time depends on whether the economy is in a growth expansion or a growth contraction. Over the 1869-1975 sample, 49 percent of the time this growth rate was greater than average, consistent with Falk's (1986) and DeLong and Summers's (1986) finding of little or no skewness in the growth rates of U.S. GNP and industrial production. The asymptotic marginal significance levels ( $p$-values) for the likelihood ratio test applied to bivariate models are reported in table 1 . The first four columns are for the test statistics based on the exclusion restrictions in that equation alone, and the final column corresponds to the test statistic for the system as a whole. The results reported under the heading "Levels" are based on (9), using the nominal interest rate, inflation, and log real per capita income and money. The results reported under "Differences" are based on the formulation (10) and use the interest rate, inflation, and the growth rates of real per capita money and income. Five of the six systems considered reject the null hypothesis of no nonlinearities at the 5 percent level in both the levels and the differences formulations when $p=3$. However, the primary sources of these rejections 
TABLE 1

Marginal Significance Levels for Bivariate Tests for Business Cycle Time, $1869-1975$

\begin{tabular}{|c|c|c|c|c|c|}
\hline \multirow[b]{2}{*}{ MODEL } & \multicolumn{4}{|c|}{ EQUATION } & \multirow[b]{2}{*}{ SYSTEM } \\
\hline & $y$ & $m$ & $r s$ & infl & \\
\hline \multicolumn{6}{|l|}{$\begin{array}{l}\text { 1. } y, m: \\
\text { Levels: }\end{array}$} \\
\hline$p=1$ & .4799 & .3592 & $\ldots$ & $\ldots$ & .6475 \\
\hline$p=3$ & .3848 & .2966 & $\ldots$ & $\ldots$ & .3492 \\
\hline \multicolumn{6}{|c|}{ Differences: } \\
\hline$p=1$ & 6349 & .4245 & $\ldots$ & $\ldots$ & .6323 \\
\hline$p=3$ & .8726 & .1665 & $\ldots$ & $\ldots$ & .5349 \\
\hline \multicolumn{6}{|l|}{$\begin{array}{l}\text { 2. } y, r s: \\
\text { Levels: }\end{array}$} \\
\hline$p=1$ & .3037 & $\ldots$ & $.0002^{*}$ & $\ldots$ & $.0004^{*}$ \\
\hline$p=3$ & .3432 & $\ldots$ & $.0013 *$ & $\ldots$ & $.0034 *$ \\
\hline \multicolumn{6}{|c|}{ Differences: } \\
\hline$p=1$ & .3036 & $\ldots$ & $.0002 *$ & $\ldots$ & $.0002^{*}$ \\
\hline$p=3$ & .3650 & $\ldots$ & $.0003^{*}$ & $\ldots$ & $.0007 *$ \\
\hline \multirow{2}{*}{\multicolumn{6}{|c|}{$\begin{array}{l}\text { 3. } y \text {, infl: } \\
\text { Levels: }\end{array}$}} \\
\hline & & & & & \\
\hline$p=1$ & .2438 & $\ldots$ & $\ldots$ & .6173 & .3320 \\
\hline$p=3$ & .1456 & $\ldots$ & $\ldots$ & $.0003 *$ & $.0008^{*}$ \\
\hline \multicolumn{6}{|c|}{ Differences: } \\
\hline$p=1$ & .5748 & $\cdots$ & $\ldots$ & .7840 & .8037 \\
\hline$p=3$ & .7622 & $\ldots$ & $\ldots$ & $.0028^{*}$ & $.0353 *$ \\
\hline \multicolumn{6}{|l|}{$\begin{array}{l}\text { 4. } m, r s: \\
\text { Levels: }\end{array}$} \\
\hline$p=1$ & $\ldots$ & .4937 & $.0000^{*}$ & $\ldots$ & $.0001 *$ \\
\hline$p=3$ & $\ldots$ & .3798 & $.0001^{*}$ & $\ldots$ & $.0006^{*}$ \\
\hline \multicolumn{6}{|c|}{ Differences: } \\
\hline$p=1$ & $\ldots$ & .3817 & $.0001^{*}$ & $\ldots$ & $.0006^{*}$ \\
\hline$p=3$ & $\ldots$ & $.0151 *$ & $.0159 *$ & $\ldots$ & $.0011 *$ \\
\hline \multicolumn{6}{|l|}{$\begin{array}{l}\text { 5. } m \text {, infl: } \\
\text { Levels: }\end{array}$} \\
\hline$p=1$ & $\ldots$ & .3851 & $\ldots$ & .5861 & .4393 \\
\hline$p=3$ & $\ldots$ & $.0088 *$ & $\ldots$ & $.0804^{\dagger}$ & $.0329 *$ \\
\hline \multicolumn{6}{|c|}{ Differences: } \\
\hline$p=1$ & $\ldots$ & .4374 & $\ldots$ & .1250 & .2065 \\
\hline$p=3$ & $\ldots$ & $.0066^{*}$ & $\ldots$ & $.0270^{*}$ & $.0178 *$ \\
\hline \multirow{2}{*}{\multicolumn{6}{|c|}{$\begin{array}{l}\text { 6. } r s \text {, infl: } \\
\text { Levels: }\end{array}$}} \\
\hline & & & & & \\
\hline$p=1$ & $\ldots$ & $\ldots$ & $.0000^{*}$ & .6219 & $.0002 *$ \\
\hline$p=3$ & $\cdots$ & $\ldots$ & $.0000^{*}$ & $.0132^{*}$ & $.0000^{*}$ \\
\hline \multicolumn{6}{|c|}{ Differences: } \\
\hline $\begin{array}{l}p=1 \\
p=3\end{array}$ & $\cdots$ & $\cdots$ & $.0000^{*}$ & .6522 & $.0002 *$ \\
\hline$p-3$ & $\cdots$ & $\cdots$ & $.0000^{*}$ & $.0107 *$ & $.000)^{*}$ \\
\hline
\end{tabular}

Note.-Annual data, described in the text. Income $(y)$ and money $(m)$ are real per capita, in logarithms. The interest rate $(r s)$ is the nominal short-term rate on cornmercial paper, and the inflation rate (infl) is based on the implicit income deflator. The values of $p$ refer to the orders of the lag polynomials in eqq. (9) (levels) and (10) (differences).

* Significant at the 5 percent level.

${ }^{\dagger}$ Significant at the 10 percent level. 
are the interest rate and inflation equations. The income equations exhibit little evidence of time scale nonlinearities, and the restrictions in the money equation are violated only when money appears with the short rate or with inflation. While the $p$-values vary somewhat, the conclusions from these tests are similar for the specifications of levels and differences. ${ }^{7}$

Although these diagnostic tests indicate nonlinearities consistent with the time deformation hypothesis, the evidence is mixed. First, none of the tests indicate a role for the time scale transformation in the income equations. Second, the apparent strength of the effect of the time scale indicator variable differs from equation to equation within a system. While a system as a whole might nevertheless indicate rejection, this variation in the importance of the cyclical indicator across equations suggests the absence of a systemwide cyclical time scale.

\section{Estimated Reduced-Form Models in Business Cycle Time}

The parameters of the time deformation model of Section I were estimated by asymptotic maximum likelihood for a variety of time scale transformations. ${ }^{8}$ Interest rates, GNP, and inflation were modeled as flows, and money was modeled as a stock. ${ }^{9}$ A difficulty with the

${ }^{7}$ Tests on trivariate systems present a picture similar to table 1 . (These and other unreported results discussed in the text are available from the author on request.) In each of the four trivariate combinations of income, money, interest rate, and inflation, it is possible to reject at the 5 percent level the null of no time deformation in the system of equations when three lags are included. As in the bivariate systems, the primary variables indicating time scale sensitivity are the interest rate and inflation. In contrast, the time scale variables do not enter significantly (at the 5 percent level) any of the income equations. The results for the money equations fall between these two extremes, yielding significant results except in the system with income and interest rates.

${ }^{8}$ Estimation was done using the Kalman filtering algorithm in Stock (1985), which generalizes to time deformation models the algorithm of Harvey and Stock (1985). All specifications are in levels with a linear time trend. Alternative frequency domain approaches to estimating higher-order systems are developed by Hansen and Sargent (1981) and Bergstrom (1983). Except in special cases, however, frequency domain algorithms do not generalize to irregularly spaced observations or time deformation models. To reduce the expense of repeated maximization, the estimates in tables 3-6 were obtained using a two-step procedure. In the first step the latent process was estimated by maximum likelihood, subject to the constraint that $\Delta g(t)=1$. The parameters $\mathbf{c}$ were estimated in the second step by constraining the latent process to be that estimated in the first step and optimizing only over $\mathbf{c}$. Thus the likelihood ratio statistics are a lower bound on the value that would obtain under full joint estimation.

${ }^{9}$ The choice of a stock or flow model requires some judgment. Since the logarithm of GNP is used, annual GNP is modeled as a geometric average of instantaneous GNP over the year. While treating GNP in levels rather than in logarithms would yield a truer model of GNP measurement, this would not address the exponential growth and heteroscedasticity in the series. The reported commercial paper rate is an annual average of weekly or daily observations, depending on the sample period, so it was modeled 
TABLE 2

In-Sample Performance of Models without Business Cycle Time Effects

\begin{tabular}{|c|c|c|c|c|}
\hline \multirow[b]{2}{*}{ MODEL } & \multicolumn{4}{|c|}{ VARIABLE } \\
\hline & $\begin{array}{c}y \\
\text { MSE } \\
Q(10)\end{array}$ & $\begin{array}{c}m \\
\text { MSE } \\
Q(10)\end{array}$ & $\begin{array}{c}\text { infl } \\
\text { MSE } \\
Q(10)\end{array}$ & $\begin{array}{c}r s \\
\text { MSE } \\
Q(10)\end{array}$ \\
\hline \multicolumn{5}{|l|}{ Discrete: } \\
\hline 1. Univariate $\operatorname{AR}(p)$ & $\begin{array}{r}3.79 \\
17.39\end{array}$ & $\begin{array}{l}2.02 \\
6.66\end{array}$ & $\begin{array}{l}2.17 \\
5.81\end{array}$ & $\begin{array}{l}.106 \\
3.56\end{array}$ \\
\hline $\begin{array}{l}\text { 2. } \operatorname{VAR}(1) \\
(y, m, \text { infl, } r s)\end{array}$ & $\begin{array}{r}3.25 \\
18.57\end{array}$ & $\begin{array}{l}1.88 \\
7.64\end{array}$ & $\begin{array}{l}2.11 \\
5.51\end{array}$ & $\begin{array}{l}.120 \\
15.69\end{array}$ \\
\hline Continuous: & & & & \\
\hline 3. Univariate $\operatorname{AR}(p)$ & $\begin{array}{r}3.38 \\
12.18\end{array}$ & $\begin{array}{r}2.85 \\
10.03\end{array}$ & $\begin{array}{l}2.12 \\
4.02\end{array}$ & $\begin{array}{l}.128 \\
13.99\end{array}$ \\
\hline $\begin{array}{l}\text { 4. } \operatorname{VAR}(1) \\
(y, m, \text { infl, } r s)\end{array}$ & $\begin{array}{l}3.64 \\
8.65\end{array}$ & $\begin{array}{r}3.06 \\
13.00\end{array}$ & $\begin{array}{l}2.14 \\
6.43\end{array}$ & $\begin{array}{l}.132 \\
16.29\end{array}$ \\
\hline
\end{tabular}

NotE. $-Q(10)$ refers to the Box-Pierce statistic with 10 degrees of freedom, and the MSE is $\times 10^{-3}$. All models include linear time trends. The autoregressive order $p$ is 3 for $m$, infl, and $r$, and is 1 for $y$. The models were estimated for the period 1872-1975, except the univariate $\operatorname{AR}(3)$ models with inflation and the interest rate, which were estimated for 1873-1975. Earlier observations were used for initial conditions as necessary.

estimation of continuous-time models with equally spaced data is the "aliasing" problem, in which there can be multiple, equally tall peaks of the likelihood (see Priestley 1981; Hansen and Sargent 1983). As a result, the parameters of the continuous-time process with no time deformation will in general be locally but not globally identifiable. Since the potential multiple peaks under the null of no time deformation have the same value of the likelihood function, however, likelihood ratio statistics testing for nonzero time deformation parameters will still be valid in the sense of providing an upper bound on the corresponding marginal significance levels. ${ }^{10}$

As a benchmark, four sets of estimated models without time deformation are presented in table 2. Because the discrete and continuous-

as a flow. The annual inflation rate represents the integral of the instantaneous inflation rate over the year, so it was also modeled as a flow. The proper model for money is less clear since the early observations represent averages of quarterly values, later becoming averages of monthly data. Accordingly, in the reported results the logarithm of real per capita money was treated as a stock. (For a related discussion, see Friedman [1983].) The models with money in tables $3-5$ were also estimated treating money as a flow. Although the estimated parameters of the latent process in the stock and flow models differ, the time transformations were generally similar to those reported here. While lags of money were not as significant in the time transformations of the flows model, interest rates, GNP, and $I_{t-1}$ were more significant.

${ }^{10}$ Under certain conditions, aliasing does not occur if the data are sampled at randomly spaced irregular intervals (e.g., Brillinger 1970; Masry 1980). While these results are for independently and identically distributed random sampling intervals and thus do not apply directly to the general time deformation model, they do suggest that the effectively irregular sampling in economic time induced by nonlinear time transformations might mitigate the aliasing problem. 
TABLE 3

Estimated Time Scale Transformations: Univariate Models with Business Cycle Time Variables

\begin{tabular}{|c|c|c|c|c|c|c|}
\hline \multirow{2}{*}{$\begin{array}{l}\text { DEPENDENT } \\
\text { VARIABLE }\end{array}$} & \multicolumn{3}{|c|}{$\mathbf{z}_{t-1}$} & \multirow[b]{2}{*}{$Q(10)$} & \multirow[b]{2}{*}{ MSE } & \multirow{2}{*}{$\begin{array}{c}\text { LikELIHOOD } \\
\text { Ratio } \\
\text { StatistiC }\end{array}$} \\
\hline & $I_{t-1}$ & $I G_{t-1}$ & $\mathrm{NBER}_{t}$ & & & \\
\hline \multirow[t]{4}{*}{$y$} & $\begin{array}{c}-.001 \\
(.001)\end{array}$ & & $\ldots$ & 13.02 & 3.39 & .17 \\
\hline & $\ldots$ & $\begin{array}{c}.001 \\
(.001)\end{array}$ & $\ldots$ & 11.67 & 3.36 & .63 \\
\hline & & $\ldots$ & $\begin{array}{l}.004^{*} \\
(.002)\end{array}$ & 11.50 & 3.25 & $4.63 *$ \\
\hline & $\begin{array}{c}-.003 \\
(.002)\end{array}$ & $\begin{array}{l}.003 \\
(.002)\end{array}$ & $\begin{array}{l}.004^{\dagger} \\
(.002)\end{array}$ & 11.94 & 3.20 & $6.69^{\dagger}$ \\
\hline \multirow[t]{4}{*}{$m$} & $\begin{array}{l}.000 \\
(.001)\end{array}$ & . & $\ldots$ & 10.03 & 2.85 & .06 \\
\hline & $\ldots$ & $\begin{array}{l}.005 \\
(.006)\end{array}$ & . & 9.92 & 2.83 & .66 \\
\hline & & $\ldots$ & $\begin{array}{l}.001 \\
(.005)\end{array}$ & 10.09 & 2.85 & .06 \\
\hline & $\begin{array}{c}-.000 \\
(.001)\end{array}$ & $\begin{array}{l}.001 \\
(.001)\end{array}$ & $\begin{array}{l}.000 \\
(.001)\end{array}$ & 10.73 & 2.82 & 1.09 \\
\hline \multirow[t]{4}{*}{ infl } & $\begin{array}{r}-.062 \\
(.083)\end{array}$ & $\ldots$ & $\ldots$ & 4.15 & 2.10 & .52 \\
\hline & $\ldots$ & $\begin{array}{l}.036 \\
(.079)\end{array}$ & $\cdots$ & 3.82 & 2.12 & .20 \\
\hline & & $\cdots$ & $\begin{array}{c}.157 * \\
(.079)\end{array}$ & 4.51 & 2.08 & $3.90 *$ \\
\hline & $\begin{array}{c}-.033 \\
(.022)\end{array}$ & $\begin{array}{l}.019 \\
(.033)\end{array}$ & $\begin{array}{c}.148^{*} \\
(.073)\end{array}$ & 4.45 & 2.06 & $8.69 *$ \\
\hline \multirow[t]{4}{*}{ rs } & $\begin{array}{l}.003^{\dagger} \\
(.002)\end{array}$ & $\cdots$ & $\cdots$ & 14.82 & .124 & $3.13^{+}$ \\
\hline & $\ldots$ & $\begin{array}{l}.003^{*} \\
(.001)\end{array}$ & $\ldots$ & 14.14 & .124 & $3.90 *$ \\
\hline & & $\ldots$ & $\begin{array}{l}.003 \\
(.002)\end{array}$ & 15.28 & .126 & 2.46 \\
\hline & $\begin{array}{l}.001 \\
(.002)\end{array}$ & $\begin{array}{l}.003^{*} \\
(.001)\end{array}$ & $\begin{array}{c}.001 \\
(.001)\end{array}$ & 14.24 & .123 & 4.89 \\
\hline
\end{tabular}

Note.-Based on univariate continuous-time autoregressions of orders reported in table 2, subject to time deformation of the form (3). Standard errors are in parentheses. The likelihood ratio statistic tests the hypothesis that $\mathbf{c}=0$.

* Coefficients are significantly different from zero at the 5 percent level.

${ }^{\dagger}$ Coefficients are significantly different from zero at the 10 percent level.

time models impose different restrictions on the autocorrelation functions, these two types of models yield somewhat different results; for example, while the mean square error (MSE) for income is lower in the continuous than in the discrete-time univariate models, this is reversed for the VAR(1) models.

Estimated univariate models with business cycle time scale variables are presented in table 3 . The entries in the first three columns of the 
table are the estimated coefficient vectors $\mathbf{c}$ in the time scale transformation (3) for various choices of $\mathbf{z}_{t-1}$, where NBER $\mathrm{N}_{t}$ is the BurnsMitchell time scale (5). The indicator variables play an important role in determining the time scales of interest rates and, to a lesser extent, inflation. When all three business cycle variables are included in the time scale transformations, the results vary sharply across variables: the sole statistically significant contributor to the interest rate time scale is the growth cycle switching variable, while for inflation and income the important variable is the NBER time scale variable. Overall, then, the results based on business cycle-related variables are mixed: no single cyclical time scale variable has significant time deformation effects in all univariate models.

Tables 4 and 5 represent an attempt to discover whether the business cycle nonlinearities evident in tables 1 and 3 arise because other important variables have been omitted from the time scale transformation. Looking across all the univariate models, one sees that each of the variables exhibits time scale nonlinearities. The time scale transformations differ, however, from one series to the next. No cyclical variable forms the sole basis for these estimated time scales, and the importance of the cyclical variables to the time scale transformation differs across models. Indeed, the interest rate plays a more important role across univariate time transformations than do any of the cyclical measures.

Table 6 provides evidence against the importance of the business cycle variables to a common time scale transformation. This table contains the results of estimating first-order, four-dimensional stochastic differential equation systems for these mixed stock/flow variables evolving on a common economic time scale. Although both $I G$ and NBER (but not $I$ ) are statistically significant when considered alone, their coefficients are small. Furthermore, their effect vanishes statistically when lagged endogenous variables enter into the time transformation (models 5-7). As in the univariate results, interest rates continue to play an important role in generating these nonlinearities; in addition, the growth rate of income also enters linearly rather than as a switching variable. Finally, the likelihood ratio statistics for models 5-7 indicate that the hypothesis that all the time scale coefficients are zero can be rejected at the 1 percent level.

In summary, the support for a common time scale based solely on the expansion/contraction indicators is limited. The results of including the NBER variable in the time transformation are more difficult to interpret: while its time transformation coefficients can be highly significant in univariate models, this variable is determined by future turning points and thus would be expected to have predictive content. Whether a modified version of this transformation based on pre- 


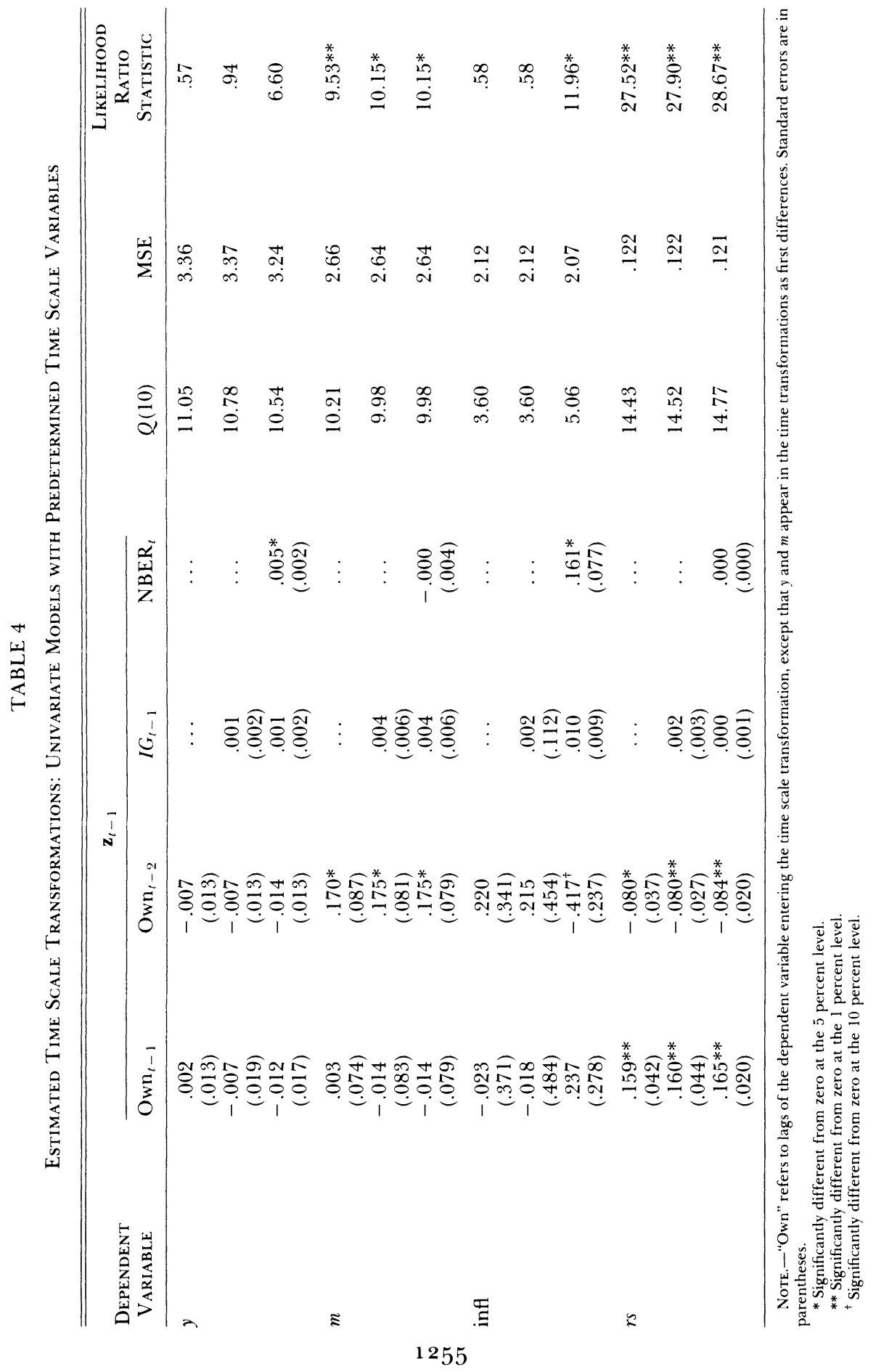




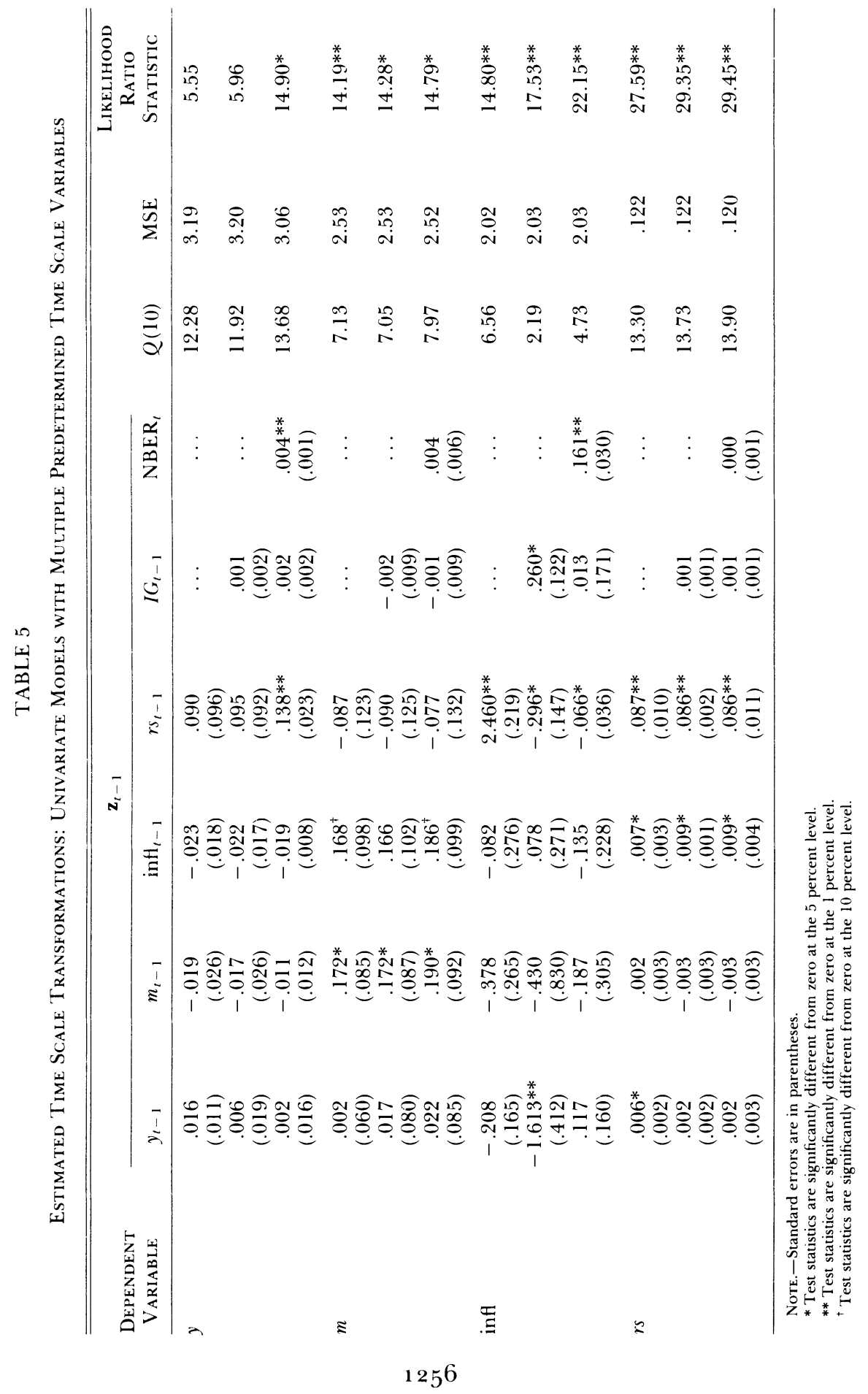




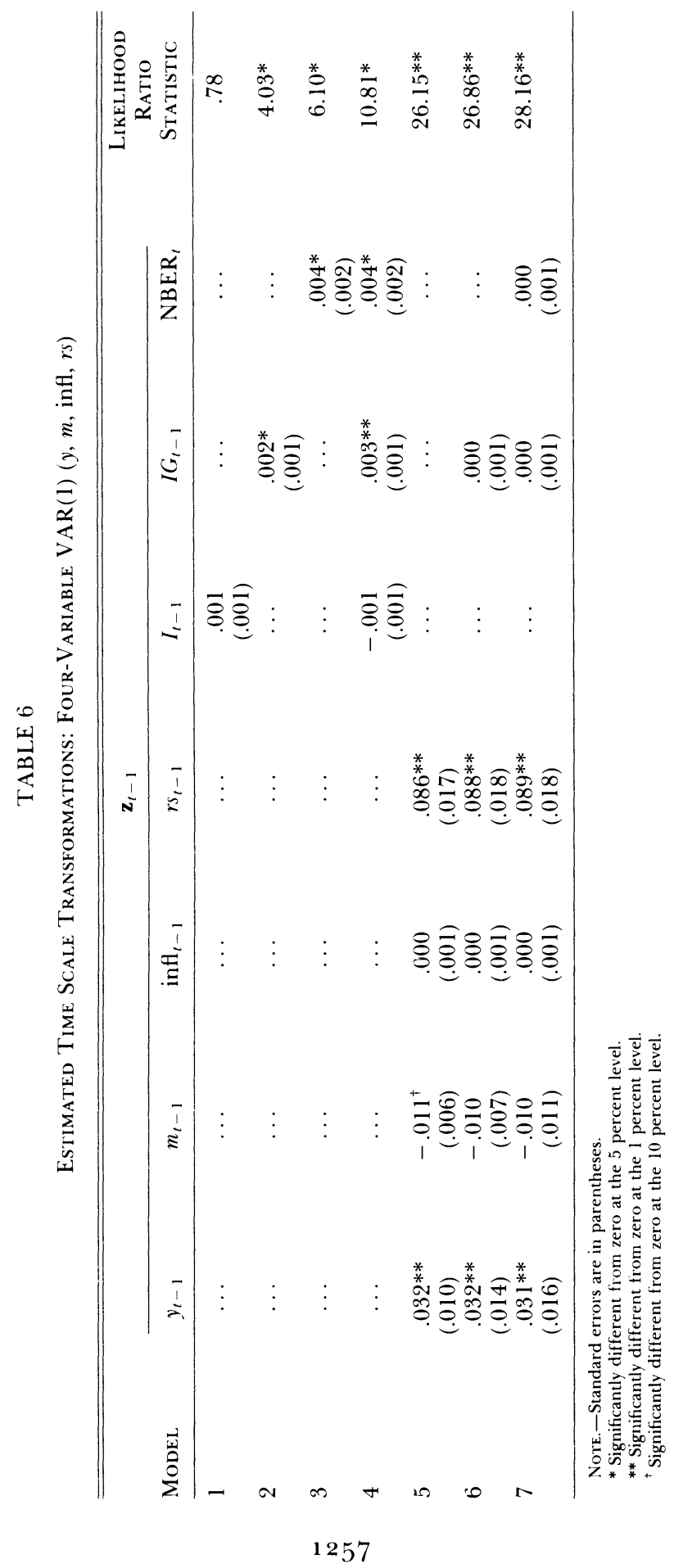


dicted turning points would be as important as the NBER variable is an open question. Finally, time scales based on lagged endogenous variables can have pronounced effects; the key variables in these time transformations are lags of the short-term interest rate and real GNP.

\section{Conclusions}

This paper has used classical statistical techniques to estimate nonlinear time scale transformations of the general form (3), in which the time transformations depend on the history of the process. Any conclusions from this investigation must therefore be tempered by the possibility that there are other, more appropriate specifications, in particular, transformations based on different functional forms or transformations that incorporate unobservable stochastic elements. Subject to this caveat, however, three conclusions can be drawn from these results. First, this data set provides little support for the proposition that there is a common macroeconomic time scale based solely on business cycle-related variables. When considered alone, the cyclical measures can have an effect in determining the time scale transformations for some macroeconomic variables. However, this effect diminishes or disappears when more general time scale transformations are considered.

Second, of the two contraction/expansion indicator variables, the growth cycle indicator exhibits stronger effects when included in the time scale transformations. However, the effects of both indicator variables are small.

Third, when more general forms of time scale transformations based on lagged endogenous variables are considered, the effect of introducing these nonlinearities can be pronounced. Although the results differ across univariate and multivariate models, the key variables determining these economic time scales are the short-term rate of interest and, to a lesser extent, lagged income growth, with both having an accelerating effect on economic time. It is premature to speculate about the existence of a single macroeconomic time scale. However, the evidence presented here suggests that, if there is such an economic time scale, it will be substantially more general than time scales based solely on the business cycle.

\section{Appendix}

\section{Diagnostic Tests for Economic versus Calendar Time}

This Appendix motivates the diagnostic tests applied in Section III. It is assumed that $\Delta g(t)$ has the approximation (4) (local to $c=0$ ), with $m=1$. 
The calendar time representation for a first-order time deformation model when the observable process is a stock variable is obtained by solving (2) with $r=1$. Letting $\mathbf{A} \equiv \mathbf{A}_{1}$ for $s>s^{\prime}$, the process satisfies

$$
\boldsymbol{\xi}(s)=\boldsymbol{\delta}\left(s^{\prime}, s-s^{\prime}\right)+e^{\mathbf{A}\left(s-s^{\prime}\right)} \boldsymbol{\xi}\left(s^{\prime}\right)+\int_{s^{\prime}}^{s} e^{\mathbf{A}(s-r)} d \boldsymbol{\zeta}(r),
$$

where the real parts of the roots of $\mathbf{A}$ are assumed to be negative so that the process is stable, where the matrix exponentials are defined by their Taylor series expansions, and where the function $\boldsymbol{\delta}\left(s^{\prime}, s-s^{\prime}\right)$ depends on the parameters A, $\boldsymbol{\beta}_{0}$, and $\boldsymbol{\beta}_{1}$ (see, e.g., Bergstrom 1983). Letting $s=g(t), s^{\prime}=g(t-1)$, and substituting $\mathbf{Y}_{t}=\boldsymbol{\xi}(g(t))$ into (Al), one obtains

$$
\mathbf{Y}_{t}=\boldsymbol{\delta}[g(t-1), \Delta g(t)]+e^{\mathbf{A} \Delta g(t)} \mathbf{Y}_{t}+\mathbf{v}_{t}
$$

where

$$
\mathbf{v}_{t}=\int_{g(t-1)}^{g(t)} e^{\mathbf{A}[g(t)-r]} d \zeta(r)
$$

so that

$$
E \mathbf{v}_{t} \mathbf{v}_{t}^{\prime}=\mathbf{F}_{t}=\int_{g(t-1)}^{g(t)} e^{\mathbf{A}\lfloor g(t)-r\rfloor} \mathbf{\Sigma} e^{\mathbf{A}[g(t)-r] \prime} d r .
$$

The first-order multivariate time deformation model (A2) has intercept, time trend, autoregressive coefficients, and error covariance matrix that are functions of the time scale transformation and thus of $\tilde{z}_{t-1}$. The tests arise by considering the linearization of (A2) for small time deformations. When one expands the coefficients in $c$ around $c=0$ and collects terms, (A2) can be approximately written as

$$
\begin{aligned}
\mathbf{Y}_{t} \cong & \boldsymbol{\delta}_{0}+c \boldsymbol{\delta}_{1} \tilde{z}_{t-1}+\boldsymbol{\delta}_{2} t+c \boldsymbol{\delta}_{3} \sum_{s=1}^{t-1} \tilde{z}_{s} \\
& +c \boldsymbol{\delta}_{4} t \tilde{z}_{t-1}+e^{\mathbf{A}} \mathbf{Y}_{t-1}+c \mathbf{A} e^{\mathbf{A}} \tilde{z}_{t-1} \mathbf{Y}_{t-1}+\mathbf{v}_{t},
\end{aligned}
$$

where $\boldsymbol{\delta}_{i}, i=0, \ldots, 4$, are constants. If the latent process does not include a time trend, then $\boldsymbol{\beta}_{1}=0$ and (A3) reduces to

$$
\mathbf{Y}_{t} \cong \boldsymbol{\delta}_{0}+c \boldsymbol{\delta}_{1} \tilde{z}_{t-1}+e^{\mathbf{A}} \mathbf{Y}_{t-1}+c \mathbf{A} e^{\mathbf{A}} \tilde{z}_{t-1} \mathbf{Y}_{t-1}+\mathbf{v}_{t}
$$

If $c=0$, then the terms involving $\tilde{z}_{t-1}$ will not appear in (A3) or (A4), and $\mathbf{Y}_{t}$ will have a (restricted) linear discrete time vector autoregressive representation. Thus, when the latent process is first order and the variables are stocks, a simple test for time deformation obtains by estimating unrestricted versions of (A3) (or [A4], as appropriate) using ordinary least squares equation by equation and testing whether the terms involving $\tilde{z}_{t-1}$ enter significantly.

A somewhat more formal motivation for the tests comes from considering the score test of the hypothesis that $c=0$. Since $\mathbf{v}_{t}$ is conditionally normal, the $\log$ likelihood is $\mathscr{L}=-1 / 2 \Sigma_{t} \mathbf{v}_{t}^{\prime} \mathbf{F}_{t}^{-1} \mathbf{v}_{t}-1 / 2 \Sigma_{t} \ln \left|\mathbf{F}_{t}\right|$, plus terms that are bounded in probability. The score test obtains by considering the derivative of $\mathscr{L}$,

$$
\frac{\partial \mathscr{L}}{\partial c}=-\sum_{t}\left(\frac{\partial \mathbf{v}_{t}}{\partial c}\right)^{\prime} \mathbf{F}_{t}^{-1} \mathbf{v}_{t}-1 / 2 \sum_{t} \mathbf{v}_{t}^{\prime}\left(\frac{\partial \mathbf{F}_{t}^{-1}}{\partial c}\right) \mathbf{v}_{t}-1 / 2 \sum_{t} \frac{\partial\left(\ln \left|\mathbf{F}_{t}\right|\right)}{\partial c},
$$


where the terms depending on $c$ are evaluated at $c=0$. Since $\partial \mathbf{v}_{t} /\left.\partial c\right|_{c=0}=$ $-\partial E\left(\mathbf{Y}_{t} \mid \mathbf{Y}_{t-1}, \tilde{z}_{t-1}\right) /\left.\partial c\right|_{c=0}$, the first term in (A5) tests for the nonlinearities in the conditional expectation of $\mathbf{Y}_{t}$, local to $c=0$. These terms are precisely those multiplied by $c$ in (A3) and (A4). The remaining two terms in (A5) test for conditional heteroscedasticity induced by the time scale transformation. A test focusing solely on these latter terms would resemble Engle's (1982) score test for ARCH errors. Thus tests based on (A3) and (A4) can be interpreted as tests of restrictions that imply those involving the conditional expectations terms in the score test.

In most applications, including those in Section III, it will be desirable to relax the assumption that the latent process is first-order. In addition, at least some of the variables in the process might be flows. Without time deformation, when the system is generated by (2) and the variables are stocks, the discrete-time process will in general have a (vector) $\operatorname{ARMA}(r, r-1)$ representation; when the system includes flows, it will have a discrete-time $\operatorname{ARMA}(r, r)$ representation. Since the objective here is to develop regressionbased diagnostics, these vector autoregressive moving average models are approximated by vector autoregressions with deterministic terms. The regressions (9) and (10) thus generalize (A3) and (A4) by testing for $\tilde{z}_{t-1}$ entering the vector autoregressions analogously to the first-order point-in-time model.

\section{References}

Allais, Maurice. "A Restatement of the Quantity Theory of Money." A.E.R. 56 (December 1966): 1123-57.

$\rightarrow$ Barro, Robert J. "Inflation, the Payments Period, and the Demand for Money." J.P.E. 78 (November/December 1970): 1228-63.

Bergstrom, A. R., ed. Statistical Inference in Continuous Time Economic Models. Amsterdam: North-Holland, 1976.

- "Gaussian Estimation of Structural Parameters in Higher Order Continuous Time Dynamic Models.” Econometrica 51 (January 1983): 117-52.

Breiman, Leo. Probability and Stochastic Processes: With a View toward Applications. Boston: Houghton Mifflin, 1969.

Brillinger, David R. "The Spectral Analysis of Stationary Interval Functions." In The Proceedings of the Sixth Berkeley Symposium on Mathematical Statistics and Probability, vol. 1, Theory of Statistics. Berkeley: Univ. California Press, 1970.

Burns, Arthur F., and Mitchell, Wesley C. Measuring Business Cycles. New York: Columbia Univ. Press (for NBER), 1946.

Cagan, Phillip. "The Monetary Dynamics of Hyperinflation." In Studies in the Quantity Theory of Money, edited by Milton Friedman. Chicago: Univ. Chicago Press, 1956.

$\rightarrow$ Chetty, V. K., and Heckman, James J. "A Dynamic Model of Aggregate Output Supply, Factor Demand and Entry and Exit for a Competitive Industry with Heterogeneous Plants." J. Econometrics 33 (October/ November 1986): 237-62.

Clark, Peter K. "A Subordinated Stochastic Process Model with Finite Variance for Speculative Prices.” Econometrica 41 (January 1973): 135-55.

Cox, David R., and Lewis, Peter A. W. The Statistical Analysis of Series of Events. London: Methuen, 1966.

DeLong, J. Bradford, and Summers, Lawrence H. "Are Business Cycles Symmetric?" In The American Business Cycle: Continuity and Change, edited by Robert J. Gordon. Chicago: Univ. Chicago Press (for NBER), 1986. 
Engle, Robert F. "Autoregressive Conditional Heteroscedasticity with Estimates of the Variance of United Kingdom Inflation." Econometrica 50 (July 1982): 987-1007.

$\rightarrow$ Falk, Barry, "Further Evidence on the Asymmetric Behavior of Economic Time Series over the Business Cycle." J.P.E. 94 (October 1986): 10961109.

Feller, William. An Introduction to Probability Theory and Its Applications. Vol. 2. 2d ed. New York: Wiley, 1971.

$\rightarrow$ Flood, Robert P., and Garber, Peter M. "An Economic Theory of Monetary Reform.” J.P.E. 88 (February 1980): 24-58.

Friedman, Milton. "Monetary Variability: United States and Japan.” J. Money, Credit and Banking 15 (August 1983): 339-43.

Friedman, Milton, and Schwartz, Anna J. Monetary Trends in the United States and the United Kingdom: Their Relation to Income, Prices, and Interest Rates, 1867-1975. Chicago: Univ. Chicago Press (for NBER), 1982.

Hansen, Lars P., and Sargent, Thomas J. "Formulating and Estimating Continuous Time Rational Expectations Models." Staff Report no. 75. Minneapolis: Fed. Reserve Bank Minneapolis, October 1981.

- "The Dimensionality of the Aliasing Problem in Models with Rational Spectral Densities." Econometrica 51 (March 1983): 377-87.

$\rightarrow$ Harvey, A. C., and Stock, James H. "The Estimation of Higher Order Continuous Time Autoregressive Models." Econometric Theory 1 (April 1985): 97-112.

$\rightarrow$ Koopmans, Tjalling C. "Measurement without Theory." Rev. Econ. and Statis. 29 (August 1947): 161-72.

Lewis, Peter A. W., ed. Stochastic Point Processes: Statistical Analysis, Theory, and Applications. New York: Wiley-Interscience, 1972.

Mandelbrot, Benoit B. "Comments on: "A Subordinated Stochastic Process Model with Finite Variance for Speculative Prices,' by Peter K. Clark." Econometrica 41 (January 1973): 157-59.

$\rightarrow$ Masry, E. "Discrete-Time Spectral Estimation of Continuous-Time Processes-the Orthogonal Series Method.” Ann. Statis. 8 (September 1980): 1100-1109.

Moore, Geoffrey H. Business Cycles, Inflation, and Forecasting. 2d ed. Studies in Business Cycles no. 24. Cambridge, Mass.: Ballinger (for NBER), 1983.

$\rightarrow$ Neftçi, Salih N. "Are Economic Time Series Asymmetric over the Business Cycle?" J.P.E. 92 (April 1984): 307-28.

$\longrightarrow$ "Is There a Cyclical Time Unit?" Carnegie-Rochester Conf. Ser. Public Policy 24 (Spring 1986): 11-48.

$\rightarrow$ Pindyck, Robert S. "Risk, Inflation, and the Stock Market." A.E.R. 74 (June 1984): 335-51.

$\rightarrow$ Poterba, James M., and Summers, Lawrence H. "The Persistence of Volatility and Stock Market Fluctuations.” A.E.R. 76 (December 1986): 1142-51.

Priestley, Maurice B. Spectral Analysis and Time Series. London: Academic Press, 1981.

$\rightarrow$ Schultze, Charles L. "Some Macro Foundations for Micro Theory." Brookings Papers Econ. Activity, no. 2 (1981), pp. 521-76.

Stock, James H. "Dynamic Economic Models Subject to Time Deformation." Ph.D. dissertation, Univ. California, Berkeley, 1983.

. "Estimating Continuous Time Autoregressions Subject to Time Deformation: An Application to Postwar U.S. GNP." Manuscript. Cambridge, Mass.: Harvard Univ., November 1985. 